\title{
КОНФОРМАЦІЙНІ ВЛАСТИВОСТІ НАПІВГНУЧКИХ ПОЛІМЕРІВ: ЧИСЛОВІ СИМУЛЯЦІЇ
}

\author{
В. БЛАВАЦЬКА, ${ }^{1}$ Х. ГАЙДУКІВСЬКА, ${ }^{2}$ Ю. ГОЛОВАЧ ${ }^{1}$ \\ ${ }^{1}$ Інститут фізики конденсованих систем НАН України \\ (Вул. Свєнціцъкого, 1, Львів 79011) \\ $\mathbf{2}$ Львівський національний університет ім. I. Франка, фізичний факультет \\ (Вул. Кирила і Мефоділ, 8, Львів 79005)
}

УдК 538.91

(C) 2012

Досліджено конформаційні властивості напівгнучких полімерів застосовуючи граткову модель випадкових блукань без самоперетинів (self-avoiding walks - SAW) із енергією згинання $\varepsilon$, залежною від взаємоорієнтації послідовних кроків. Застосовано алгоритм Розенблюта із збідненням та збагаченням (PERM). Проаналізовано випадки, коли згини енергетично вигідні $(\varepsilon<0)$ та невигідні $(\varepsilon>0)$, і обговорено деталі переходу "клубок-стержень" та властивості "надгнучкого" стану.

\section{1. Вступ}

Багато полімерів, які зустрічаються у хімічній та біологічній фізиці, характеризуються лінійною хімічною архітектурою, і тому поводяться як гнучкі ланцюжки. Після полімеризації гнучка полімерна макромолекула може набувати багато різних конформацій. Конформацією називають просторову структуру полімера, що визначається взаємними розташуваннями мономерів [1-3]. Типові приклади гнучких полімерів - це синтетичні полімери із вуглецевою основою, наприклад поліетилен, в якого сусідні атоми вуглецю можуть вільно повертатись навколо одиночних $\sigma$-зв'язків відносно основи. Статистичні властивості гнучких полімерів в умовах хорошого розчинення нині детально досліджено [4-6]. Зокрема показано, що типові довгі гнучкі полімерні ланцюжки в хороших розчинниках формують заплутані клубки, лінійний розмір яких, для прикладу середньоквадратична відстань між кінцями ланцюжка $\left\langle R^{2}\right\rangle$, підлягає закону скейлінгу відносно кількості мономерів $N$ :

$\left\langle R^{2}\right\rangle \sim N^{2 \nu}$,

де $\nu$ - універсальний показник, значення якого залежить лише від вимірності простору $d(\nu(d=3)=$ $0,5882 \pm 0,0011[7])$.

В останні роки значну увагу приділяють напівгнучким полімерам, оскільки багато важливих органічних макромолекул, таких як ДНК та білки, нале- жать до цього класу [8,9]. Як правило, такі макромолекули характеризуються масивними бічними групами (для прикладу, радикалами амінокислотних залишків) вздовж вуглецевої основи. Напівгнучкими вважаються полімери із достатньо великим значенням персистентної довжини $l_{p}$, тому вона стає сумірною із іншими важливими масштабами довжини, що визначають поведінку макромолекули. Загалом, персистентна довжина напівгнучких полімерів може сягати кількох десятків нанометрів (наприклад, механічна персистентна довжина макромолекул ДНК порядку 50 нм [9]). Також деякі синтетичні полімери характеризуються жорсткістю на невеликих масштабах вздовж ланцюжків (полістирол із боковими фенольними групами).

Встановлено, що просторові конформаційні властивості гнучких полімерних макромолекул у хороших розчинниках можна успішно досліджувати застосовуючи граткову модель випадкових блукань без самоперетинів (self-avoiding walk - SAW). Незважаючи на простоту моделі, вона дозволяе із високою точністю отримати кількісні значення низки універсальних просторових характеристик полімерів. Халлі та інші [10] запропонували узагальнити модель SAW для опису напівгнучких полімерів, увівши різні статистичні ваги для “транс"- (сусідні мономери з'єднуються без утворення прямого кута) і “гош"-кроків (у цьому випадку полімер згинається). Персистентна довжина таких "упереджених" блукань (biased self-avoiding walk - BSAW) подана як обернено-пропорційна величина до ймовірності “гош"-кроків, а скейлінговий закон для $\left\langle R^{2}\right\rangle$ було запропоновано записати у вигляді

$\left\langle R^{2}\right\rangle=N^{2} f\left(\frac{N}{l_{p}}\right)$.

Тут $f\left(N / l_{p}\right)$ - скейлінгова функція, що описує перехід між двома основними режимами: при довжині ланцюжка, набагато більшій за $l_{p}$, будь-який полімер поводиться як гнучкий, підлягаючи скейлінговому за- 


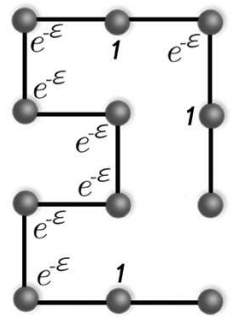

Рис. 1. Схематичне зображення траєкторії SAW у $d=2$. Kожному повороту зіставляється енергія згину $\varepsilon$. Кількість згинів (“гош"-кроків) - 7. Кожному прямому зв'язку (“транс"-кроку) відповідає енергія згинання $\varepsilon=0$

кону (1), тоді як при довжині ланцюжка, набагато меншій за персистентну, полімер досягає межі жорсткого стержня з $\left\langle R^{2}\right\rangle \sim N^{2}$. Скейлінгові властивості BSAW досліджували як чисельно [11-16], так і аналітично [17-19].

Незначна модифікація моделі BSAW була запропонована Джакометті і Марітаном [20] шляхом введення енергії згинання $\varepsilon$, пов'язаної із кожним кроком вбік від попереднього напрямку руху, так що кожен "поворот" траєкторії пов'язаний зі статистичною вагою $\mathrm{e}^{-\varepsilon}$ (див. рис. 1). Персистентна довжина у такій моделі $є$ функцією енергї згину $l_{p} \sim \mathrm{e}^{\varepsilon}$ (при $\varepsilon>0)$. Випадок $\varepsilon=0$ відповідає гнучкому ланцюжку $\left(l_{p}=1\right)$, при $\varepsilon \gg 0$ згини енергетично невигідні i ланцюжки є повністю жорсткими $\left(l_{p} \rightarrow \infty\right)$, тоді як при $\varepsilon \ll 0$ згини стають енергетично вигідними і з'являються "надгнучкі", дуже кучеряві ланцюжки зі згинами на кожному кроці. Цікавий приклад фізичної реалізації такої моделі можна знайти у біополімеpax, просторова структура яких значно визначається пептидними зв'язками між аміно- та карбоксильними групами окремих складових ланок. Саме ці зв'язки приводять до утворення видовжених, стержнеподібних структур, так званих $\alpha$-спіралей. Руйнування цих зв'язків за певних умов зовнішнього середовища (розчину) може приводити до згинання, скручування макромолекули, що й можна описати як перехід "стержень-клубок" у межах моделі, що розглядається. Коли перша границя тісно пов'язана із переходом "клубок-стержень", згаданим вище, значно менше відомо про другий випадок, коли згини вигідні. Особливо цікаве питання про типову форму таких "надгнучких" полімерних ланцюжків досі не розв'язане.

У цій статті розглянемо граткову модель напівгнучких полімерів із параметром згинання $\varepsilon$, що керує переходом між станами жорсткості та гнучкості. За- стосовуючи числові симуляції, оцінюємо залежність кількості згинів від параметра $\varepsilon$ і аналізуємо властивості "надгнучкої фази".

\section{2. Метод}

Для дослідження конформаційних властивостей блукань із самоуниканням на сталій гратці використовуємо збіднено-збагачений метод Розенблюта (PERM) [21], що поєднує оригінальний Розенблют-Розенблют алгоритм зростаючого ланцюжка [22] і контроль росту популяцій [23]. Кожен $n$-й мономер розташовується на випадково вибраному сусідньому вузлі попереднього $(n-1)$-го мономера $(n \leq N$, де $N$ - повна довжина ланцюжка). Якщо цей випадково вибраний вузол уже зайнятий, він оминається без відкидання усього ланцюжка і кожній конформації на $n$-му кроці приписано вагу $W_{n}$ :

$W_{n}=\prod_{l=1}^{n} m_{l} \mathrm{e}^{-\varepsilon_{l}\left(1-\cos \theta_{l}\right)}$,

де $m_{l}$ - кількість вільних вузлів гратки для розміщення $l$-го мономера, $\theta_{l}$ - кут між $l$-м і $l-1$-м кроком і $\varepsilon_{l}$ - енергія згинання $l$-го кроку, напрямленого інакше, аніж попередній, що відповідає випадку $\theta=\pi / 2$.

Ріст припиняється, коли досягнуто повної довжини ланцюжка $N$ (або при $n<N$, коли вже немає вільних вузлів, щоб зробити наступний крок), тоді починаємо будувати наступний ланцюжок із тієї самої точки, де починали попередній.

Усереднення за конформаціями для довільної досліджуваної величини матиме вигляд

$\langle(\ldots)\rangle=\frac{1}{Z_{N}} \sum_{k=1}^{M} W_{N}^{k}(\ldots), \quad Z_{N}=\sum_{k=1}^{M} W_{N}^{k}$.

Тут підсумовування ведеться за усіма можливими конформаціями $N$-крокового $\mathrm{SAW}\left(M \sim 10^{5}\right.$ у нашому випадку). Зауважимо, що в літературі, присвяченій дослідженню структурно-невпорядкованих систем, для означення процедури (4) прийнято вживати вираз "конфігураційне усереднення" [24]. Однак, оскільки у фізиці полімерів термін "конфігурація" пов'язаний із фіксованою послідовністю розташування мономерів вздовж ланцюга [3], тут і надалі використовуватимемо термін "конформаційне усереднення" для позначення усереднення (4).

Флуктуації ваги зростаючого ланцюжка в PERM компенсуються зменшенням числа конформацій 3 




Рис. 2. Кількість згинів у полімерному ланцюжку як функція енергії згинання $\varepsilon$ при різній кількості мономерів $N$ в $d=2$

надто малою вагою та збільшенням кількості конформацій з великою вагою через їх копіювання. Ці копії створюються у процесі побудови ланцюжка і продовжують зростати незалежно одна від одної. Збіднення та збагачення здійснюються вибором порогових значень $W_{n}^{<}$i $W_{n}^{>}$, які поступово оновлюються у процесі симуляцій. Якщо поточна вага $W_{n} n$-мономерного ланцюжка менша за $W_{n}^{<}$, то ланцюжок відкидається з імовірністю 1/2, у протилежному випадку він зберігається, а його вага подвоюється. Якщо $W_{n}^{<}$перевищує $W_{n}^{>}$, то конформація подвоюється, а вагу кожної 3 копій беруть як половину початкової ваги. У всіх інших випадках побудова ланцюжка продовжується без збільшення чи зменшення кількості зразків.

Для оновлення порогових значень використовуємо ті самі умови, що й у $[25,26]: W_{n}^{>}=C\left(Z_{n} / Z_{1}\right)\left(c_{n} / c_{1}\right)^{2}$ i $W_{n}^{<}=0,2 W_{n}^{>}$, де $c_{n}$ позначає кількість створених ланцюжків довжиною $n$, а параметр $C$ контролює збіднювально-збагачувальну статистику; він відрегульований так, що у середньому за один цикл генерується 10 ланцюжків загальної довжини $N$ [26].

\section{3. Результати та їх обговорення}

Застосовуючи алгоритм PERM, проаналізовано конформаційні властивості напівгнучких SAW залежно від зміни енергії згинання $\varepsilon$ у просторі вимірності $d=2$ i $d=3$. Числові симуляції здійснювались для ланцюжків довжиною до 1000 мономерів у $d=2 \mathrm{i}$ до 600 мономерів в $d=3$. Енергія згинання в обох випадках змінювалася у межах -10, ., 10.

Для кількісного опису ступеня гнучкості чи жорсткості, оцінено кількість згинів у полімерному лан-

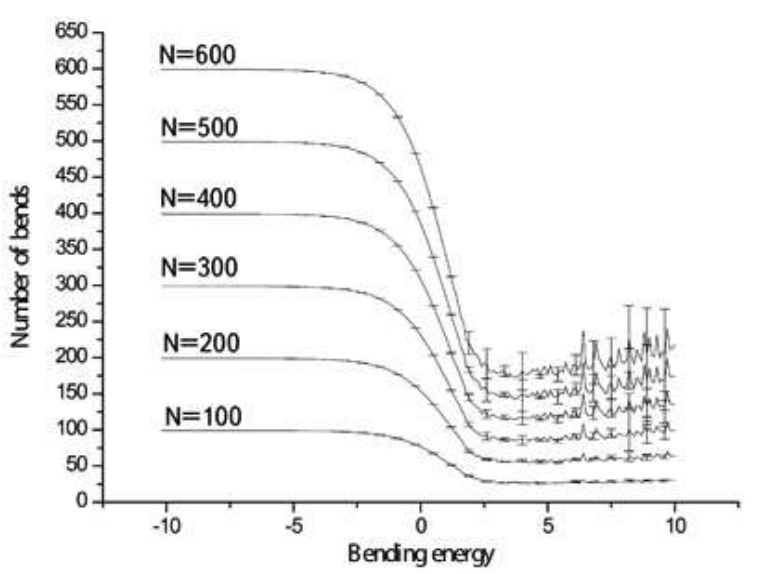

Рис. 3. Кількість згинів у полімерному ланцюжку як функція енергї згинання $\varepsilon$ при різній кількості мономерів $N$ в $d=3$

цюжку довжиною $N$, що відповідає кількості разів, коли траєкторія SAW змінює свій напрямок. На рис. 2 i 3 зображено результати симуляцій. Випадок $\varepsilon=0$ відповідає режиму гнучкого полімерного клубка, масштаб середнього розміру якого задано виразом (1). Для від'ємних значень $\varepsilon$ згинання стає ще більше вигідним. У границі $\varepsilon \ll 0$ отримуємо "надгнучкий" полімерний ланцюжок із поворотом на кожному кроці, так що кількість згинів дорівнює $N-1$ для SAW довжиною $N$. Однаково для 2- і 3 -вимірного простору можемо оцінити крайове значення $\varepsilon \simeq-3,5$, нижче якого спостерігається "надгнучкий" режим. Для додатних $\varepsilon$, коли кожен згин траєкторії приводить до зростання загальної енергії, поступово досягатиметься границя цілком жорсткого стержнеподібного полімеру. Обмеження нашого методу, однак, дозволяє вловити цю тенденцію лише для коротких ланцюжків $N \leq 100$.

У той час, коли у більшості попередніх досліджень у центрі уваги була поведінка напівгнучких полімерів за умови зростання жорсткості (відповідає випадку $\varepsilon>0$ у нашій моделі), значно меншу увагу приділяли протилежній ситуації "надгнучких" полімерів $(\varepsilon<0)$. Виникає цікаве запитання: якою є типова форма таких конформацій. У принципі можна очікувати зигзагоподібної конформації, як зображено на центральній схемі рис. 4 .

Можемо пролити світло на це питання, розглядаючи середнє число найближчих контактів $p$ (тобто, число сусідніх вузлів, зайнятих траєкторією, але не пов'язаних між собою зв'язками) типового полімерного ланцюжка. Очевидно, що для цілком прямої, стержнеподібної конформації матимемо $p=0$, тоді 


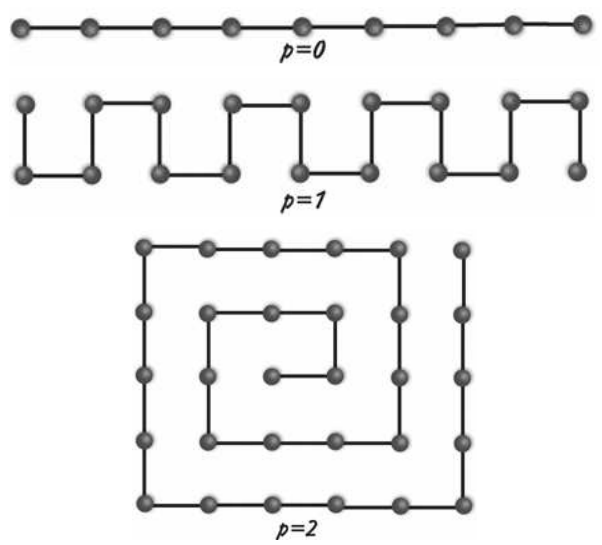

Рис. 4. Схематичне представлення траєкторії SAW в $d=2$ із кількістю найближчих контактів $p=0$ (стержнеподібна конформація), $p=1$ (зигзагоподібна конформація), $p=2$ (компактна глобула)

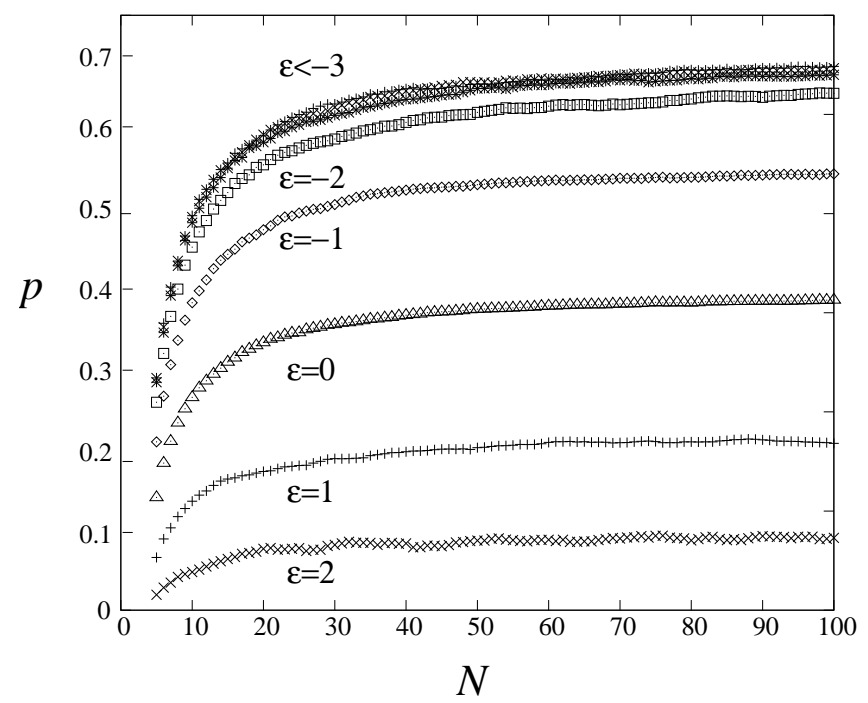

Рис. 5. Кількість найближчих контактів у траєкторії SAW в $d=2$ як функція довжини ланцюжка $N$ при різних значеннях енергії згинання $\varepsilon$

як для очікуваної зигзагоподібної структури $p=1$ (в $d=2$ ), як зображено на рис. 4 . Наші чисельні результати для величини $p$, як функції від енергії згинання $\varepsilon$ для SAW в $d=2$, наведено на рис. 5 . При $\varepsilon=0$, що відповідає традиційній проблемі SAW, кількість найближчих контактів у $d$-вимірному просторі може бути оцінена зі співвідношення

$p=2 d-1-z(d)$,

де $z(d)$ - фугативність SAW (середнє число можливостей зробити наступний крок у зростаючій траєктоpiï). I справді, для спрощеного випадку, коли трає-

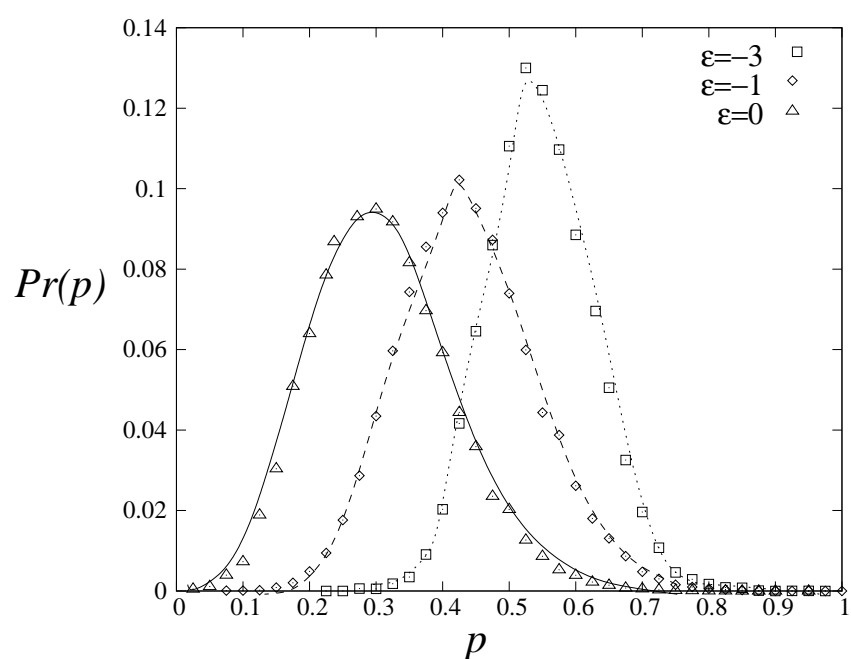

Рис. 6. Розподіл імовірності кількості найближчих контактів в траєкторії $\mathrm{SAW} з N=40$ кроків в $d=2$ для різних значень енергї згинання $\varepsilon$

кторії дозволено себе перетинати (так зване випадкове блукання), в $d$-вимірному просторі легко показати, що $z(d)=2 d$. Беручи до уваги ефект самоуникання, перш за все, заборонимо "повернення назад" на кожному кроці, що зменшує фугативність до величини $2 d-1$. Врешті, відзначимо ще один фактор, що зменшує фугативність завдяки ефекту самоуникання, це контакти з найближчими сусідами $p$. Підставляючи відоме для $d=2$ значення $z(d=2)=2,6385 \pm 0,0001$ [27] у (5), отримуємо оцінку для традиційного SAW: $p=0,3615 \pm 0,0001$. Наш результат для цього випадку при $\varepsilon=0$, отриманий апроксимацією методом найменших квадратів, дає $p=0,354 \pm 0,009$, тобто добре узгоджується. Відзначимо однак, що дана величина $є$ не універсальною, зокрема, вона залежить від типу гратки. Тому чисельне значення $p$ відображає властивості SAW на простій кубічній гратці і не може бути безпосередньо використане для опису полімерів в континуумі (в хорошому розчиннику) на відміну від універсальних параметрів (як скейлінговий показник $\nu(1))$, що прекрасно описуються гратковою моделлю SAW.

Для додатних $\varepsilon$, як очікувалось, середне число найближчих контактів прямує до нуля. Для від'ємних $\varepsilon$ величина $p$ поступово зростає аж до раніше згаданого граничного значення енергії згинання, нижче якої відбувається перехід у "надгнучку" фазу. У цій границі отримано $p=0,690 \pm 0,009$, що може описувати "розмиту" зигзагоподібну конформацію (рис. 4). Розподіли ймовірності $p$ для різних значень параметра $\varepsilon$ подано на рис. 6. 


\section{4. Висновки}

Досліджено конформаційні властивості напівгнучких полімерів застосовуючи граткову модель блукань із самоуниканнями із додатковим параметром згинання $\varepsilon$, що $є$ від'ємним для більш вигідних “гош"кроків (крок у напрямку, що не збігається з попереднім) і додатним для більш вигідних "транс"-кроків $[10,13,16,20]$. Прикладами гнучких полімерів (із енергією згину $\varepsilon=0$ в такій моделі) є (в основному синтетичні) полімери із вуглецевою основою та одиночними $\sigma$-зв'язками між сусідніми атомами вуглецю, котрі можуть вільно обертатись на цих зв'язках (поліетилен) [1-3]. Під впливом умов зовнішнього середовища такі макромолекули можуть набувати також надгнучких зигзагоподібних конформацій (що може відповідати значенню $\varepsilon<0$.) Багато органічних макромолекул (білки, ДНК) характеризуються масивними бічними групами (наприклад, радикалами амінокислотних залишків) вздовж вуглецевої основи, що приводить до зростання жорсткості (це напівгнучкі полімери, що відповідає в нашій моделі випадку $\varepsilon>0$ ) $[8,9]$. Також деякі синтетичні полімери характеризуються жорсткістю вздовж вуглецевої основи (полістирол із важкими боковими фенольними групами) [3]. Прикладами жорстких стержнеподібних макромолекул $(\varepsilon \gg 0) \in$ так звані амфіфіли, що являють собою гідрофобний вуглецевий ланцюг із полярною групою на одному кінці (фосфоліпіди).

Важливою характеристикою напівгнучких полімерів з більш вигідними “транс"-кроками є персистентна довжина $l_{p}$. На довжинах, менших за $l_{p}$, полімер досягає границі жорсткого стержня, у той час як на довжині ланцюжка, що значно перевищує персистентну, будь-який полімер поводиться як гнучкий ланцюжок, що складається із незалежних сегментів довжиною $l_{p}$. Іншим цікавим випадком є ситуація, коли "гош"-кроки є більш вигідні $(\varepsilon<0)$, тоді в границі $\varepsilon \rightarrow-\infty$ передбачаються конформації "надгнучких" ланцюжків із поворотом на кожному кроці.

Ми розглядали як перехід клубок-стержень, так і властивості "надгнучкої" фази, досліджуючи середнє число згинів у типовій конформації SAW як функцію $\varepsilon$. Було отримано граничне значення величини $\varepsilon \simeq-3,5$, нижче якого полімерний ланцюжок, що складається $3 N$ мономерів, має $N-1$ згинів і знаходиться у "надгнучкій" фазі. Це також підтверджується дослідженням середнього числа найближчих контактів $p$, що характеризує топологічні властивості полімерних конформацій. Коли для полімеру в гнучкому режимі $(\varepsilon=0)$ ця величина дорівнює $p=0,354 \pm 0,009$, вона зростає у випадку більш вигідних згинів і дорівнює $0,690 \pm 0,009$ при $\varepsilon \leq-3,5$.

Дані дослідження проведено, зокрема, за підтримки гранту Президії Національної академії наук України (В.Б.). Щиро дякуємо К. фон Ферберу (Університет м. Ковентрі, Англія) та учасникам семінару лабораторії статистичної фізики складних систем ІФКС НАН України і особливо Р. Романіку за плідні дискyciï.

1. M. Rubinstein and R.H. Colby, Polymer Physics (Oxford Univ. Press, Oxford, 2004).

2. G. Strobl, The physics of polymers. Concepts for understanding their structures and behavior (Springer, Berlin, 1997).

3. Г.М. Бартенев, С.Я. Френкель, Физика полимеров (Химия, Ленинград, 1990).

4. П. де Жен, Идеи скейлинга в физике полимеров (Мир, Москва, 1982).

5. J. des Cloizeaux, and G. Jannink, Polymers in Solutions: Their Modelling and Structure (Clarendon Press, Oxford, 1990).

6. А.Ю. Гросберг, А.Р. Хохлов, Статистическая физика макромолекул (Москва, Наука, 1989).

7. R. Guida and J. Zinn-Justin, J. Phys. A 31, 8104 (1998).

8. C. Bustamante, J.F. Marko, E.D. Siggia, and S. Smith, Science 265, 1599 (1994).

9. C.K. Ober, Science 288, 448 (2000).

10. J.W. Halley, H. Nakanishi, and R. Sandararajan, Psys. Rev. B 31, 293 (1985).

11. S.B. Lee and H. Nakanishi, Psys. Rev. B 33, 1953 (1986).

12. J. Moon and H. Nakanishi, Phys. Rev. A 44, 64271991.

13. J. W. Halley, D. Atkatz, and H. Nikanishi, J. Phys. A 23, 3297 (1990).

14. M. Dijkstra, and D. Frenkel, Phys. Rev. E 50, 349 (1994).

15. U. Bastolla and P. Grassberger, J. Stat. Phys, 89, 1061 (1997).

16. H.-P. Hsu, W. Paul and K. Binder, Europhys. Lett. 92, 28003 (2010).

17. M. L. Glassed, V. Privman, and A.M. Szpilka, J. Phys. A: Math. Gen. 19, 1185 (1986).

18. V. Privman and H.L. Frisher, J. Chem. Phys. 88, 469 (1988).

19. P.A. Wiggins and P.C. Nelson, Phys. Rev. E 73, 031906 (2006).

20. A. Giacometti and A. Maritant, J. Phys A: Math. Gen. 25, 2753 (1992).

21. P. Grassberger, Phys. Rev. E 56, 3682 (1997). 
22. M.N. Rosenbluth and A.W. Rosenbluth, J. Chem. Phys. 23, 356 (1955).

23. F.T. Wall and J.J. Erpenbeck, J. Chem. Phys. 30, 634 (1959).

24. R. Brout, Phys. Rev. 115, 824 (1959); Р. Фольк, К. фон Фербер, Ю. Головач, Успехи Физических Наук 173, 175 (2003); див. також оглядові статті у серії монографій Order, Disorder and Criticality. Advanced Problems of Phase Transition Theory (ed. Yu. Holovatch), (World Scientific, Singapore, vol. 1 (2004), vol. 2 (2007)).

25. H.P. Hsu, V. Mehra, W. Nadler, and P. Grassberger, J. Chem. Phys. 118, 444 (2007).

26. M. Bachmann and W. Janke, Phys. Rev. Lett. 91, 208105 (2003); J. Chem. Phys. 120, 6779 (2004).

27. A.J. Guttmann and J. Wang, J. Phys. A 24, 3107 (1991). Одержано 31.01.11

\section{КОНФОРМАЦИОННЫЕ СВОЙСТВА ПОЛУГИБКИХ} ПОЛИМЕРОВ: ЧИСЛОВЫЕ СИМУЛЯЦИИ

\section{В. Блавачкал, К. Гайдуковская, Ю. Головач}

$\mathrm{P}$ е з ю м е

Исследованы конформационные свойства полугибких полимеров в рамках решеточной модели случайных блужданий без самопересечений (self-avoiding walks - SAW) с энергией сгибания $\varepsilon$, зависимой от взаимоориентации последовательных шагов. Использован алгоритм Розенблюта с обеднением и обогащением (PERM). Проанализированы случаи, когда сгибы энергетически выгодны $(\varepsilon<0)$ и невыгодны $(\varepsilon>0)$, и обсуждены детали перехода "клубок-стержень" и перехода в "сверхгибкое" состояние.

\section{CONFORMATIONAL PROPERTIES OF SEMIFLEXIBLE} POLYMERS: NUMERICAL SIMULATIONS

V. Blavatska ${ }^{1}$, K. Haydukivska ${ }^{2}$, Yu. Holovatch ${ }^{1}$

${ }^{1}$ Institute for Condensed Matter Physics, Nat. Acad. of Sci. of Ukraine

(1, Svientsitskii Str., 79011 Lviv, Ukraine)

${ }^{2}$ Ivan Franko National University of Lviv, Faculty of Physics (8, Kyrylo i Mefodiy Str., Lviv 79005, Ukraine)

$\mathrm{S} u \mathrm{~mm}$ a r y

We study the conformational properties of semiflexible polymers within the lattice model of self-avoiding random walks (SAW) with bending energy $\varepsilon$ that depends on the orientation between directions of two consecutive steps. We apply the pruned-enriched Rosenbluth method (PERM). Both the cases of bending preference $(\varepsilon<0)$ and unfavorableness $(\varepsilon>0)$ are analyzed, and details of the "coil-to-rod" transition, as well as properties of the "superflexible" state, are discussed. 